\title{
Ensino e aprendizagem de eletrostática utilizando os três momentos pedagógicos de Delizoicov e Angotti
}

\section{Teaching and learning electrostatics using the three pedagogical moments of Delizoicov and Angotti}

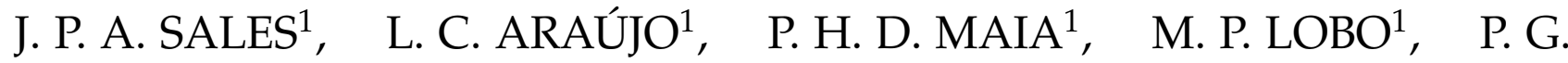 \\ BARRETO*1 \\ ${ }^{1}$ Universidade Federal do Tocantins.
}

\begin{abstract}
Resumo
Este trabalho visa desenvolver os conceitos de eletrostática em sala de aula de forma a construir o conhecimento e avaliar o grau de aprendizagem dos alunos utilizando duas aulas aplicadas aos alunos da terceira série do ensino médio. Além disso, objetiva-se também abordar como Tema Gerador a pergunta "Pode-se trabalhar os conceitos de eletrostática em sala de aula de forma a construir o conhecimento e avaliar o grau de aprendizagem dos alunos?"considerando os três momentos pedagógicos de Delizoicov e Angotti como estrutura de planejamento de aula. Para tanto, procede-se à estruturação da aula em: problematização inicial, organização do conhecimento e aplicação do conhecimento, junto com a utilização de uma demonstração experimental e de um quiz como avaliação do aprendizado. Desse modo, observa-se que a metodologia se mostrou eficaz quando analisamos os dados do diário de bordo e a aplicação do quiz.
\end{abstract}

Palavras-chave: Aprendizagem. Eletrostática. Metodologia de ensino.

*pamellagbarreto@uft.edu.br 


\begin{abstract}
This work aims to develop the concepts of electrostatics in the classroom in order to build knowledge and assess the students' degree of learning using two classes applied to students in the third grade of high school. In addition, the objective is also to address, as the Generating Theme, the question "Can the concepts of electrostatics be worked in the classroom in order to build knowledge and assess the students' degree of learning?" considering the three pedagogical moments of Delizoicov and Angotti as a lesson planning structure. To this end, the class is structured on initial problematization, organization of knowledge, and application of knowledge, together with the use of an experimental demonstration and a quiz as an assessment of learning. Thus, it is observed that the methodology proved to be effective when we analyzed the logbook data and the application of the quiz.
\end{abstract}

Keywords: Learning. Electrostatics. Teaching Methodology.

\title{
I. INTRODUÇÃO
}

Existem diversas metodologias ativas, tais como aprendizagem baseada em problemas, ensino híbrido e sala de aula invertida, que vão além do ensino tradicional. Neste artigo destacamos a experimentação e os momentos pedagógicos de Delizoicov e Angotti. Os momentos pedagógicos associados à experimentação possibilitam o aluno participar de todas as etapas da construção do conhecimento científico incluindo a contextualização e aplicação em assuntos diversos.

Ao levar em consideração as principais revistas de pesquisa em ensino nacionais e internacionais, tais como American Journal of Physics, Caderno Brasileiro de Ensino de Física, Ciência e Educação, dentre outras, esta pesquisa aponta em direção a propostas que resumem a preocupação do professor em sala de aula, de reinventar constantemente sua prática pedagógica, na busca por potencializar o aprendizado do aluno.

Nesse sentido, a disciplina de Física se destaca por aguçar ainda mais essa preocupação, graças à complexidade dos conteúdos abordados. Além disso, é comum a presença do tradicionalismo na sala de aula, não que essa forma de ensinar necessita ser extinta, mas pode ser somada a outras metodologias e aprimorar ainda mais o processo de ensino e aprendizagem da Física e/ou de outras áreas do conhecimento.

Sob essa perspectiva, este trabalho tem como Tema Gerador: "Pode-se trabalhar os conceitos de eletrostática em sala de aula de forma a construir o conhecimento e avaliar o grau de aprendizagem dos alunos?". As informações obtidas durante este processo de Investigação Temática foram realizadas por meio de análise discursiva, demonstrações experimentais e uso de simulações computacionais em que a Redução Temática foi desenvolvida tendo como referência os três momentos pedagógicos de Delizoicov e Angotti (2009), os quais se caracterizam pela problematização inicial, organização e aplicação do conhecimento.

Com o intuito de explorar os conceitos de eletrostática, organizou-se o conhecimento por meio das respostas para a problematização inicial, essas respostas foram tomadas como 
avaliação diagnóstica. A etapa de organização do conhecimento foi feita retomando os questionamentos iniciais considerando uma demonstração experimental realizada em sala de aula e uma simulação computacional.

A etapa de aplicação do conhecimento também contou com demonstração experimental e novos questionamentos foram apresentados no formato de uma avaliação do aprendizado a partir de uma plataforma de quiz, denominada kahoot ${ }^{1}$. As aulas de revisão foram ministradas para alunos da $3^{a}$ série do Ensino Médio de uma escola da rede pública de ensino.

\section{OS TRÊS MOMENTOS PEDAGÓGICOS}

Os três momentos pedagógicos é uma metodologia de ensino que foi desenvolvida por Demétrio Delizoicov e José André Peres Angotti durante o processo de formação de professores na região de Guiné-Bissau localizada na África ocidental, utilizando as ideias de Paulo Freire sobre investigação temática ${ }^{2}$. Acredita-se que por meio do diálogo aluno e professor constroem-se o conhecimento científico a respeito do tema proposto.

Existe uma necessidade na sala de aula em transformar o conhecimento empírico em conhecimento científico, e uma das formas de ocorrer essa transformação é por meio do diálogo entre professor e aluno, iniciando sempre a contextualização com o que o aluno já sabe e, partindo desse pressuposto, possibilitar a construção ou reconstrução do conhecimento científico.

Ao promover o diálogo, pode-se interpretar que, ao mesmo tempo que o aluno questiona e o professor contextualiza (constrói ou reconstrói questionamentos) sobre o saber do aluno, observa-se uma forma diferenciada no processo de ensino e aprendizagem. Baseado nessa problematização, apresenta-se os três momentos pedagógicos citados acima.

Primeiramente, com a problematização inicial, "apresentam-se as situações reais que os alunos conhecem, presenciam e que estão envolvidos nos temas, embora também exijam, para interpretá-las, a introdução dos conhecimentos contidos nas teorias científicas"(Delizoicov; Angotti e Pernambuco, 2009, p. 200). Esse momento é organizado de modo que os alunos sejam desafiados a participar, desde o início, apontando suas ideias, nas quais as expostas pelos alunos prevalecem e não são descartadas durante o processo de ensino. A meta dessa proposta é problematizar as afirmações dos alunos baseando-se nas respostas dadas por eles mesmos aos questionamentos levantados pelo professor.

Este contexto da aula é caracterizado em lançar questionamentos e não explicações, o que permite ao professor localizar as possíveis limitações e lacunas do conhecimento que vem sendo expressas pelo aluno. Delizoicov; Angotti e Pernambuco (2009, p.201) acreditam que:

\footnotetext{
${ }^{1}$ Ferramenta de avaliação gratuita na web, que permite o uso de quizzes em sala de aula e ajuda a envolver os alunos em discussões.

2"Investigação temática é a pesquisa realizada em conjunto pelo educador e comunidade sobre a realidade que os cerca e a experiência de vida do aluno. Através dela, o professor de Ciências, ou equipe de professores, pode identificar os fenômenos de maior relevância na vida sócio-cultural e econômica da população envolvida"(Delizoicov; Angotti, 1992, pg. 8).
} 
"o ponto culminante dessa problematização é fazer com que o aluno sinta a necessidade da aquisição de outros conhecimentos que ainda não detém, ou seja, procura-se configurar a situação em discussão como um problema que precisa ser enfrentado."

No segundo momento, organização do conhecimento, Delizoicov e Angotti contextualizam e trabalham o conhecimento científico de diferentes formas, afirmando que "as mais variadas atividades são empregadas, de modo que o professor possa desenvolver a conceituação identificada como fundamental para uma compreensão científica das situações problematizadas"(Delizoicov e Angotti, 1992, p.30).

Pode-se destacar algumas dessas atividades, tais como resolver exercícios, trabalhar as definições e conceitos, explicar as leis envolvidas no conteúdo, fazer exposição, passar trabalhos extraclasse, experiências, demonstrações, entre outras (Delizoicov; Angotti,1992).

Neste momento, todos trabalham juntos para a construção do conhecimento. As atividades devem ser desenvolvidas tanto pelo aluno quanto pelo professor, tornando o educando participante ativo de todo o processo de ensino e aprendizagem. No último momento pedagógico, aplicação do conhecimento, Delizoicov e Angotti (1992, p. 31) afirmam que

\begin{abstract}
"Destina-se, sobretudo, a abordar sistematicamente o conhecimento que vem sendo incorporado pelo aluno para analisar e interpretar tanto as situações iniciais que determinaram o seu estado, como as situações que não estejam diretamente ligadas ao motivo inicial, mas que são explicadas pelo mesmo conhecimento."
\end{abstract}

Nesse momento, o professor retorna às questões iniciais, para avaliar se os alunos realmente materializaram o conhecimento. Porém, o professor não trabalha apenas as questões anteriores, mas apresenta novas situações para avaliar se eles conseguem utilizar o saber em circunstâncias ainda não descritas em aula.

\title{
III. Metodologia
}

As aulas de revisão foram ministradas em uma escola pública de Ensino Médio do estado do Tocantins, a qual atende a um público diversificado de alunos. Os encontros foram realizados durante o segundo semestre do ano letivo e abordou um tema que foi ministrado no semestre anterior, com uma turma da $3^{a}$ série do Ensino Médio, perfazendo um total de 20 alunos. Por se tratar de uma pesquisa voluntária com uma carga horária extra ao tempo que os alunos permanecem na escola, não foi possível a realização da pesquisa com um número maior de participantes.

As aulas foram estruturadas de acordo com os três momentos pedagógicos de Delizoicov e Angotti e ficaram organizadas da seguinte forma: a primeira aula correspondeu ao momento pedagógico voltado à problematização inicial, com questões e situações que os alunos conheciam e que estavam envolvidas no tema, essa funcionou como uma avaliação diagnóstica dos alunos; na segunda aula, organização do conhecimento, foram retomadas as 
questões e situações anteriores, considerando os conhecimentos de Física pertinentes para a compreensão dos temas da problematização inicial; a aplicação do conhecimento aconteceu de forma sistemática, considerando como recursos o quiz kahoot e experimentos referentes às situações iniciais apresentadas.

Durante a problematização inicial, foram apresentadas questões e situações reais, considerando os conceitos de eletrostática, tais como, condutores e isolantes, formas de eletrização, série triboelétrica ${ }^{3}$, campo elétrico e força elétrica (Ramalho, 2009). Iniciamos a aula com uma avaliação diagnóstica (Silva; Matos; Almeida, 2014) com os seguintes questionamentos: O que é o raio elétrico? Como sair de forma segura de um carro que acabou de ser atingido por um raio elétrico? Por que baterias de Lítio não podem ser transportadas em aviões? O que acontece se aproximarmos um corpo eletrizado de um corpo neutro? A finalidade dessa aula foi propiciar ao aluno um distanciamento do conhecimento empírico e fazer com que ele sinta a necessidade da aquisição do conhecimento científico.

O processo de organização do conhecimento foi realizado durante a revisão dos conteúdos, quando retomamos os questionamentos iniciais e mostramos, a partir do diálogo com os alunos, os conhecimentos de Física necessários para a compreensão de cada problemática. Nessa parte do processo, foram aplicadas algumas atividades experimentais que demonstram como ocorre o processo de eletrização por indução, utilizando-se como materiais, balões, canudos e papel picado. A partir da atividade experimental e simulação computacional, foram estudados os conceitos, leis e definições dos conteúdos para a compreensão do experimento e da problematização inicial.

Nos momentos pedagógicos descritos anteriormente, foi utilizado como recurso pedagógico um datashow, para apresentar alguns recursos visuais necessários para o desenvolvimento da aula. A Figura 1 mostra os slides utilizados durante a aula para a exposição da problematização inicial e do conteúdo estudado na etapa da organização do conhecimento.

\footnotetext{
${ }^{3}$ É uma tabela que indica se os materiais adquirem cargas negativas ou positivas após sofrerem eletrização por atrito (RAMALHO, 2009).
} 


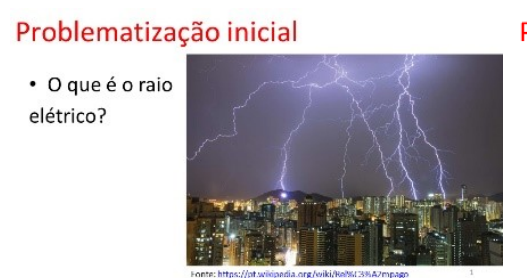

Problematização inicial

- Existe eletrização sem contato?

- Quando podemos dizer que um corpo está eletrizado?

- O que acontece se eu aproximar um corpo eletrizado de um corpo neutro?
Problematização inicial

- Como sair de forma segura de um carro que

acabou de ser atingido por um raio elétrico?
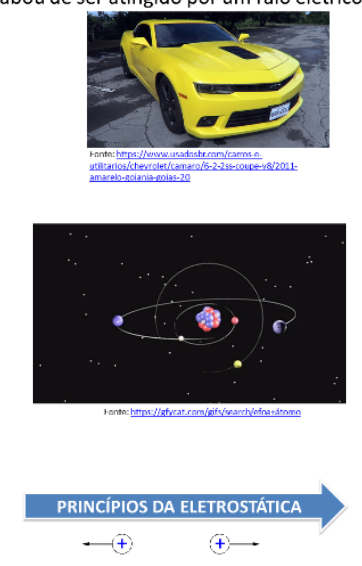

$\longrightarrow \leftrightarrow$

FORMAS DEELETRIZAÇÃO

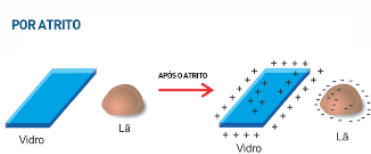

FORMAS DEELETRIZAÇÃO

porcowraro

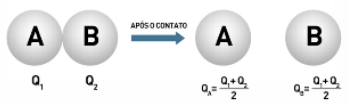

CAMPOELÉRICO

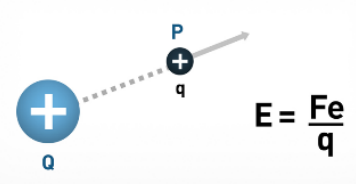

B $=(B)$

FORMAS DEELETRIZAÇÃO
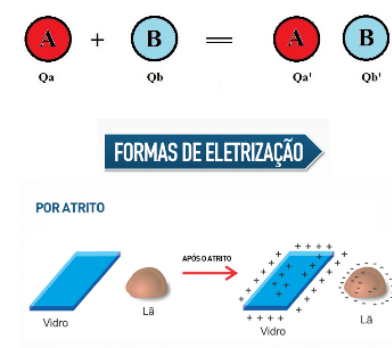

FORMAS DE ELETRIZAÇÃO

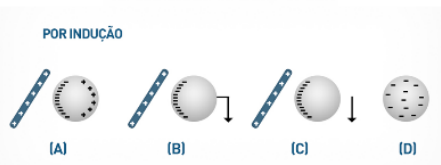

FORÇA ELÉEIRICA

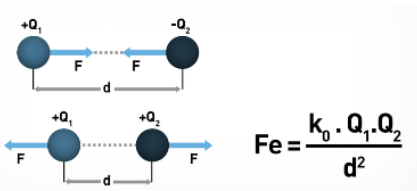

Problematização inicial

- Por que as baterias de lítio explodem? Por que

não podem ser transportadas por aviões?

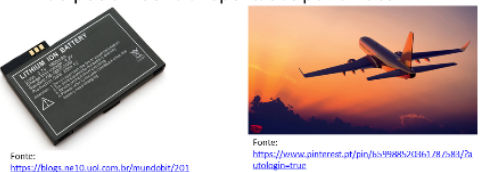

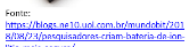
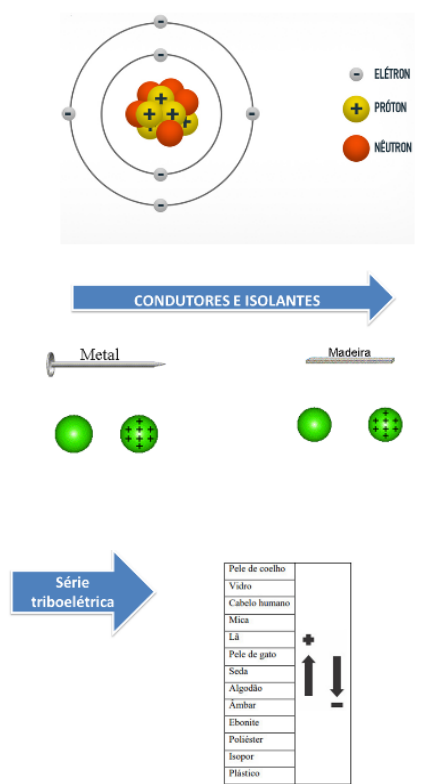

COLA

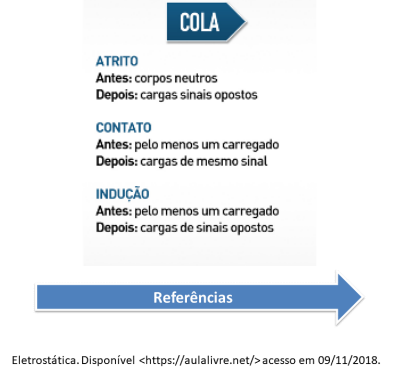

Figura 1: Slides utilizados na aula expositiva. Fonte: aula livre (2018).

Durante a aplicação do conhecimento, novos questionamentos surgiram a partir de uma demonstração experimental sobre os processos de eletrização. Nesse momento, ocorreu uma avaliação de caráter qualitativo e quantitativo (Gonçalves e Larchert, 2011), tendo em vista que foram considerados tanto os conhecimentos que os alunos construíram ao longo das atividades propostas quanto a quantidade de acertos na resolução do quiz composto por 28 questões objetivas que abordaram as situações e questões da problematização inicial, o conteúdo abordado na experimentação e algumas questões temáticas do Exame Nacional do Ensino Médio (ENEM).

Um ponto importante no desenvolvimento desta metodologia foi o plano de aula, organizado em acordo com os três momentos pedagógicos de Delizoicov e Angotti. Essa 
organização permite o professor levar em consideração os conhecimentos que os alunos já possuem, e por meio do diálogo, oportuniza que o aluno construa e/ou reelabore seus conhecimentos a partir de questionamentos.

\section{Resultados E discussões}

Para a análise dos dados, utilizamos como ferramenta o diário de bordo ${ }^{4}$, obtido a partir das problematizações iniciais (abaixo relacionadas), gravações em vídeo e um quiz avaliativo com 28 questões. As problematizações iniciais foram feitas na primeira parte da aula, com o objetivo de iniciar um diálogo com os alunos a respeito da eletrostática. A primeira análise que faremos refere-se à problematização inicial.

\section{IV.1. Problematização inicial}

A seguir relacionamos as perguntas feitas em sala de aula com o objetivo de iniciar o processo de dialogicidade (Delizoicov; Angotti,1992). É válida a ressalva de que todos os questionamentos apresentados como problematização inicial compõem o conteúdo que já foi estudado pelos alunos e aqui está sendo tratado como uma revisão.

Q1: O que é o raio elétrico? ${ }^{5}$

Q2: Como sair de forma segura de um carro que acabou de ser atingido por um raio? ${ }^{6}$

Q3: Por que as baterias de Lítio explodem e por que não podem ser transportadas por aviões? ${ }^{7}$

Q4: Existe eletrização sem contato? ${ }^{8}$

Q5: Quando podemos dizer que um corpo está eletrizado? ${ }^{9}$

Q6: O que acontece se aproximarmos um corpo eletrizado de um corpo neutro? ${ }^{10}$

O objetivo do primeiro questionamento (Q1) foi iniciar a aula com um fenômeno simples e de cunho científico que desenvolvesse nos alunos a curiosidade sobre a eletrostática. As questões Q2 e Q3 partem de uma consequência da Q1, uma situação possível de acontecer, uma aplicação direta do conteúdo já estudado. Os questionamentos que seguiram (Q4, Q5 e Q6) surgiram a partir das perguntas feitas pelos alunos, as quais acabaram se transformando em problematizações.

Essas questões foram apresentadas aos alunos como problematização inicial, as quais foram surgindo à medida que o diálogo fluiu. Quando questionados sobre "O que é o raio elétrico?", poucos alunos tentaram procurar explicar o fenômeno, já que foi a primeira pergunta proposta. Alguns relacionaram o questionamento à formação de chuvas. Abaixo, algumas respostas dos alunos para o questionamento.

Aluno 1: Quando as nuvens se tocam...

\footnotetext{
${ }^{4}$ É um caderno no qual relatamos ideias discutidas ao longo de uma aula ou curso.

${ }^{5}$ Descarga elétrica entre duas nuvens ou entre uma nuvem e o solo.

${ }^{6}$ Pular com os pés juntos e tocar ao mesmo tempo no solo para não criar uma diferença de potencial.

${ }^{7}$ Se o ânodo (carga positiva) e cátodo (carga negativa) entrarem em contato um com o outro, um descontrole térmico pode acontecer, ocasionando uma explosão.

${ }^{8}$ Sim, por indução.

${ }^{9}$ Quando ele tem excesso ou falta de elétrons.

${ }^{10}$ Eles se atraem.
} 
Aluno 2: Eu já vi algo sobre isso... não lembro... é uma descarga elétrica...

Aluno 3: O raio é o relâmpago!?...

As respostas indicam que os alunos não conseguiram relacionar os conceitos físicos aos fenômenos da natureza apresentados como questões. Porém, com as situações propostas para discussão foi possível estimular a curiosidade científica dos alunos e despertar a necessidade da aquisição de outros conhecimentos que ainda não detém.

Quando questionados sobre "Como sair de forma segura de um carro que acabou de ser atingido por um raio?", algumas respostas foram as seguintes.

Aluno 1: Eu posso ficar dentro do carro?...

Aluno 4: Vi isso em um vídeo... acho que tem que sair com os pés juntos... pra não levar choque?

Aluno 5: Ese duas pessoas tiverem no carro?...

O questionamento "Por que as baterias de Lítio explodem e por que não podem ser transportadas por aviões?", os alunos responderam em forma de pergunta.

Aluno 3: Tem relação com a pressão?

Aluno 5: Tem a ver com o campo magnético gerado pela bateria!?

O próximo questionamento estava relacionado aos processos de eletrização de um corpo, "Existe eletrização sem contato?". Neste caso, alguns alunos responderam:

Aluno 2: Por atrito!?

Aluno 3: Tem indução também.

Aluno 6: Não... acho que não tem.

Aluno 7: Condução!?

Seguimos o processo de problematização, partindo e complementando os questionamentos levantados pelos alunos. Assim, surgiram perguntas como "Quando podemos dizer que um corpo está eletrizado? O que acontece se aproximarmos um corpo eletrizado de um corpo neutro?", de modo que os alunos se manifestaram da seguinte forma:

Aluno 1: O corpo tá eletrizado quando ele tem elétrons...

Aluno 8: O corpo neutro fica eletrizado!?...

\section{IV.2. Organização do conhecimento}

Durante a revisão dos conteúdos, quando os questionamentos iniciais foram retomados, uma demonstração experimental foi feita em sala de aula sobre o processo de eletrização por indução e a partir dessa atividade, os conceitos, leis e definições relacionados ao conteúdo foram estudados. Um datashow foi utilizado como material de apoio para apresentar os slides com os principais conteúdos e formulações, e a simulação "Balões e Eletricidade Estática", disponível na plataforma Phet Colorado ${ }^{11}$.

Diante de toda a exposição e discussão, surgiram outros questionamentos e assim foi possível verificar que os alunos estavam interessados em compreender os conhecimentos de Física relacionados às situações abordadas na problematização inicial. Esse interesse ficou ainda mais visível quando foi apresentada a demonstração experimental utilizando materiais do dia a dia. Além disso, as análises qualitativas dos argumentos dos estudantes construídos ao

\footnotetext{
${ }^{11}$ https://phet.colorado.edu/sims/html/balloons-and-static-electricity/latest/balloons-and-staticelectricity $t_{B}$ R.html
} 
longo das atividades propostas permitiram constatar que houve desconstrução dos conceitos equivocados apresentados pelos alunos durante a problematização inicial.

\section{IV.3. Aplicação do conhecimento}

O quiz foi a principal aplicação que utilizamos no desenvolvimento da metodologia deste trabalho. Os alunos responderam 28 questões objetivas relacionadas tanto às problematizações iniciais quanto ao conteúdo de eletrostática. O quadro abaixo apresenta as questões utilizadas no quiz.

1) As principais partículas elementares constituintes do átomo são:

a) Prótons, Elétrons e Carga elétrica

b) Prótons, Nêutrons e Elétrons

c) Elétrons, Nêutrons e Átomos

d) Nêutrons, Negativa e Positiva

2) Indique os processos pelos quais um corpo pode ser eletrizado.

a) Atrito, Contato e Aterramento

b) Indução, Aterramento e Eletroscópio

c) Atrito, Contato e Indução

d) Contato, Aquecimento e Indução

3) Qual o valor da constante "K"?

a) $9,0 \times 109 \mathrm{Nm} 2 / \mathrm{C} 2$ b) $9,0 \times 107 \mathrm{Nm} 2 / \mathrm{C} 2$

c) $9,0 \times 108 \mathrm{Nm} 2 / \mathrm{C} 2$ d) $9,0 \times 1010 \mathrm{Nm} 2 / \mathrm{C} 2$

4) Como é definido o campo elétrico na eletrostática?

a) $E=F e . q$ b) $E=q / F e$ c) $E=F e+q$ d) $E=F e / q$

5) Qual é a unidade de medida do campo elétrico no SI?

a) $\mathrm{N} / \mathrm{C}$ b) $\mathrm{C} / \mathrm{N}$ c) $\mathrm{C}$ d) $\mathrm{N}$

6) O que se perde e se ganha nos processos de eletrização?

a) Prótons b) Elétrons c) Nêutrons d) Neutrinos

7) Qual o nome do processo de eletrização que ocorre quando esfregamos dois corpos distintos?

a) Contato b) Indução c) Atrito d) Subdução

8) Qual alternativa contém um condutor e um isolante respectivamente?

a) madeira e borracha b) ouro e prata

c) alumínio e borracha d) aço e cobre

9) A matéria em seu estado normal não manifesta propriedades elétricas, isso significa que:

a) Ela é constituída somente de nêutrons

b) Ela possui mais elétrons que nêutrons

c) Ela possui mais elétrons que prótons

d) Ela possui quantidades iguais de prótons e elétrons

10) A descarga elétrica que ocorre de nuvem para nuvem é chamada:

10) A descarga elétrica que ocorre de nuvem
a) Relâmpago b) Raio c) Trovão d) Reflexão

a) Relâmpago b) Raio c) Trovão d) Reflexão
11) Se um corpo se encontra eletrizado positivamente, pode-se afirmar que ele possui:

a) Falta de prótons b) Excesso de elétrons

c) Falta de elétrons d) Excesso de nêutrons

12) Um isolante elétrico:

a) Não pode ser carregado eletricamente

b) Não contém elétrons

c) Não pode ser metálico

d) Tem que estar no estado sólido

13) Você penteia os cabelos usando um pente plástico. O que ocorre como pente e com o cabelo?

a) Ambos se eletrizam positivamente

b) Ambos se eletrizam negativament

c) Apenas o cabelo ficará eletrizado

d) Um deles ficará positivo e o outro negativo

14) Corpos eletrizados por atrito, contato e indução ficam carregados com cargas de sinais:

a) iguais, iguais e iguais

b) contrários, iguais e contrários

c) contrários, iguais e iguais

c) contrários, iguais e iguais
d) contrários, contrários e contrários

d) contrários, contrários é

a) Um conjunto de cargas iguais e de sinais contrários

b) Um conjunto de cargas iguais e de sinais iguais

c) Um conjunto de cargas diferentes e de sinais contrários

d) Um conjunto de cargas diferentes e de sinais iguais
16) "Substância que possui amplo número de elétrons livres"é chamado de: a) isolante b) condutor c) Ânodo d) Cátodo

17) Existe eletrização sem atrito

a) Não, pois atrito é a única forma de eletrizar um corpo

b) Não, já que no contato e na indução também ocorre atrito

c) Sim, contato e indução

18) Quando podemos dizer que um corpo está eletrizado?

a) Quando possui falta de nêutrons

b) Quando possui excesso ou falta de elétrons

c) Quando possui excesso de nêutrons

d) quando possui falta de spin

19) Qual a melhor definição para um átomo neutro?

a) Excesso de elétrons

b) Excesso de prótons

c) Número de prótons igual ao número de elétrons

d) Inexistência de prótons e elétrons

20) Uma substância que não permite que os elétrons passem através dela é chamada de:

a) Isolante b) Indutor

c) Condutor d) Eletrizada

21) Cargas se atraem.

a) Iguais b) Similares c) Neutras d) Opostas

22) Assinale a alternativa CORRETA sobre o conceito de carga elétrica.

a) É uma propriedade da matéria

b) É a quantidade de elétrons em um corpo

c) É o que é transportado pela corrente elétrica

d) É o que se converte em energia elétrica em um circuito

23) Qual processo de eletrização está representado a seguir:

a) Eletrização por atrito

b) Equipotencialização

c) Eletrização por indução

c) Eletrizaçãão por induçãao por contato

24) Se a distância entre duas cargas iguais for dobrada, o módulo da força F será:

a) $\mathrm{F} / 4 \mathrm{~b}$ ) $\mathrm{F} / 2 \mathrm{c}$ ) $4 \mathrm{~F}$ d) $2 \mathrm{~F}$

25) Cargas se repelem

a) Semelhantes b) opostas

c) Iguais d) Equipotenciais

26) Segundo a Lei de Coulomb a FORÇA é:

a) Diretamente proporcional ao quadrado da distância

b) Independente da distância entre as cargas

c) Inversamente proporcional ao quadrado da distância

d) Depende apenas da carga fonte

27) Qual o valor da carga elementar?

a) $1,6 \times 10-18 \mathrm{C}$ b) $1,6 \times 10-20 \mathrm{C}$

c) $1,6 \times 10-19 \mathrm{C}$ d) $1,6 \times 10-21 \mathrm{C}$

28)Grandezas que possuem limite para a sua divisão em partes menores são chamadas de:

a) Grandezas quantizadas

b) Grandezas discretas

c) Grandezas contínuas

d) Grandezas elementares

Os alunos responderam o quiz individualmente. O gráfico 1 mostra o percentual de acertos e erros por aluno. 


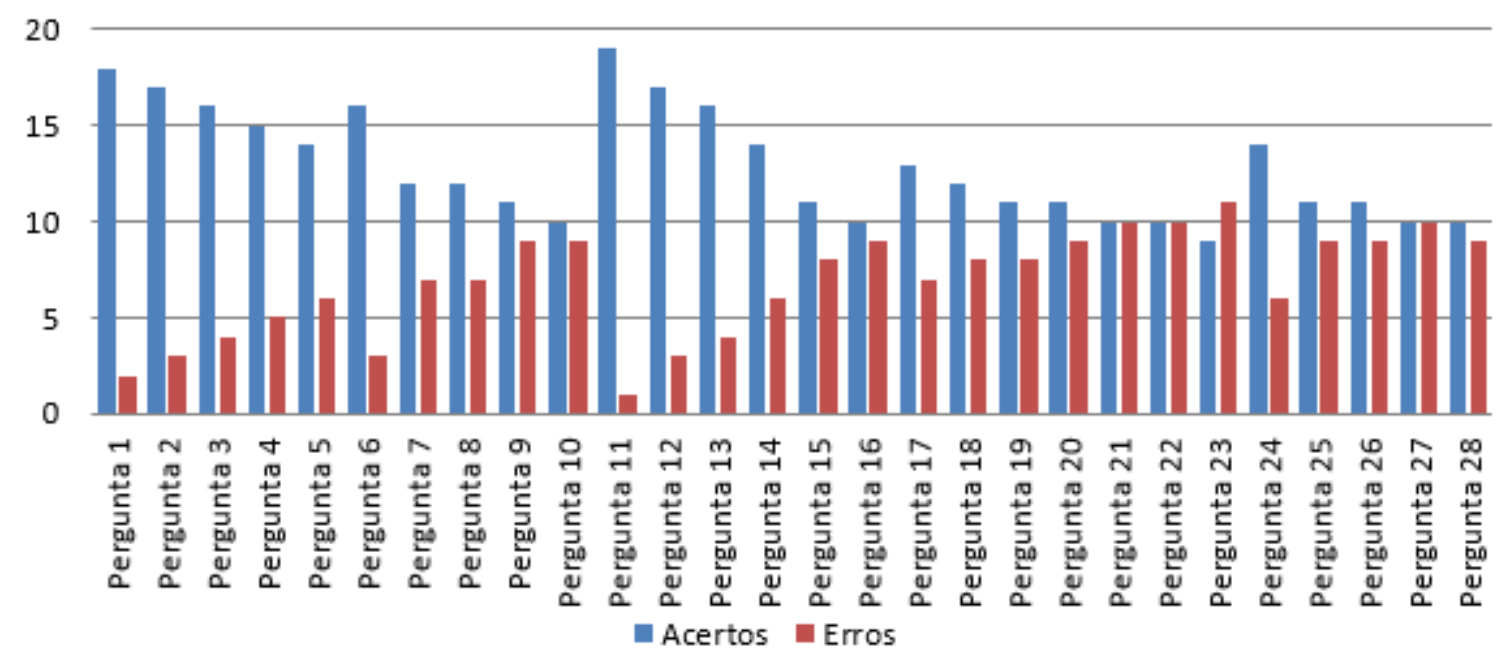

Figura 2: Percentual de erros e acertos por aluno com a aplicação do quis.

De maneira geral, o gráfico 1 revela que a quantidade de acertos superou os erros em boa parte das perguntas. As questões que tiveram altos percentuais de erros foram posteriormente contextualizadas para sanar as dúvidas dos alunos. O gráfico revela ainda que a questão com maior quantidade de acertos, questão 11, consistia em caracterizar um corpo que se encontra eletrizado positivamente, assunto esse que foi abordado na demonstração experimental. A questão com menor quantidade de acertos, questão 23, consistia em analisar uma imagem e definir o tipo de processo de eletrização, o que também foi abordado na demonstração experimental.

É possível constatar ainda que os erros e acertos dos alunos oscilaram em relação às questões que foram ou não abordadas na problematização inicial. Diante disso, e da comparação entre o tipo de pergunta e o gráfico que relaciona os erros e acertos dos alunos, considera-se que houve a aplicação do conhecimento e não apenas a memorização por parte dos alunos. Merece destaque ainda que, dos 20 alunos que participaram, apenas um não obteve o número de acertos igual ou maior do que o número de erros, como mostram as barras em vermelho no gráfico.

\section{CONSIDERAÇÕES FINAIS}

Neste trabalho apresentamos e analisamos a aplicação de uma proposta didática estruturada nos três momentos pedagógicos de Delizoicov e Angotti (1992). O objetivo foi avaliar o aprendizado do aluno com o uso dessa metodologia e verificar sua eficácia com relação à construção do conhecimento, o qual ficou comprovado durante o terceiro momento pedagógico.

Foi possível verificar que a problematização inicial serviu como fonte geradora de novas questões e fez com que os alunos sentissem a necessidade de adquirir novos conhecimentos, obedecendo a proposta inicial dos três momentos pedagógicos propostos neste trabalho.

Para tanto, o planejamento da aula foi essencial para as discussões levantadas em sala de aula, pois nele destacamos os tópicos essenciais para uma aula estruturada em problematização inicial, organização e aplicação do conhecimento. Porém, mesmo obtendo 
resultados bastante satisfatórios com a aplicação do quiz, existem alguns aspectos que merecem ser repensados, como a participação de uma maior quantidade de alunos durante a execução das atividades propostas.

\section{REFERÊNCIAS}

DELIZOICOV, D.; ANGOTTI, J. A. Física. São Paulo: Cortez, 1992.

DELIZOICOV, D.; ANGOTTI, J. A.; PERNAMBUCO, M. M. Ensino de ciências: fundamentos e métodos. São Paulo: Cortez, 2009.

GONÇALVES, A. L.; LARCHERT, J. M. Avaliação da aprendizagem: Pedagogia, vol. 6 - EAD / Elaboração de conteúdo. Ilhéus, BA: EDITUS, 2011.

RAMALHO, J. F. Os Fundamentos da Física. V. 3. Eletricidade, introdução à física moderna e análise dimensional. 10. Ed. São Paulo: Moderna, 2009.

SILVA, D. S. G.; MATOS, P. M. S.; ALMEIDA, D. M. Métodos avaliativos no processo de ensino e aprendizagem: uma revisão. Cadernos de Educação. Pelotas, n. 37, jan-abril, 2014. Disponível em: <https://periodicos.ufpel.edu.br/ojs2/index.php/caduc/article/view/4651> Acesso em: 26 ago., 2019. 